\title{
Folate-polyethylene glycol conjugated carboxymethyl chitosan for tumor-targeted delivery of 5-fluorouracil
}

\author{
HAI-LANG LI ${ }^{1,2}$, YA-XING HE ${ }^{1,2}$, QIAN-HONG GAO ${ }^{1,2}$ and GUO-ZHONG WU ${ }^{1}$ \\ ${ }^{1}$ Department of Radiation Chemistry and Engineering, Shanghai Institute of Applied Physics, Chinese Academy of Sciences, \\ Shanghai 201800; ${ }^{2}$ University of Chinese Academy of Sciences, Beijing 100049, P.R. China
}

Received May 13, 2013; Accepted December 5, 2013

DOI: $10.3892 / \mathrm{mmr} .2014 .1917$

\begin{abstract}
Targeted drug delivery has been evolving at an increasing rate due to its potential to reduce the minimum effective dose of a drug and its accompanying side effects. It has shown improved therapeutic efficacy at equivalent plasma concentrations; however, the development of effective targeted delivery systems has remained a major task. In this study, a drug carrier was designed and synthesized by conjugation of folate acid (FA) to carboxymethyl chitosan (CMCS) through a polyethylene glycol (PEG) spacer. The resulting conjugates were confirmed by ${ }^{1} \mathrm{H}$ nuclear magnetic resonance and infrared spectroscopy. The cytotoxicity of CMCS and CMCS-5-fluorouracil (5-FU) was determined by a crystal violet stain assay. The potential of CMCS-PEG-FA for use in the targeted delivery of 5-FU was investigated using 3-(4,5-dimethylthiazol-2-yl)-2,5-diphenyltetrazolium bromide analysis in two cell lines, HeLa and A549, which contain different numbers of folate receptors on their surfaces. The MTT results revealed that in HeLa cells, the cytotoxicity of (CMCS-5-FU)-PEG-FU cells is greater compared with CMCS-5-FU, suggesting that folate receptor-mediated endocytosis may affect the cellular uptake efficiency of 5-FU-loaded CMCS-PEG-FA. The CMCS-PEG-FA conjugates presented in this study show promise as carriers for chemotherapeutic agents due to their solubility at physiological $\mathrm{pH}$, efficiency in carrying chemotherapeutic agents, low cytotoxicity and targeting ability.
\end{abstract}

\section{Introduction}

Since its introduction by Heidelberger et al (1), 5-fluorouracil (5-FU) has been clinically used in the treatment of a range

Correspondence to: Professor Guo-Zhong Wu, Department of Radiation Chemistry and Engineering, Shanghai Institute of Applied Physics, Chinese Academy of Sciences, 2019 Jia Luo Road Shanghai 201800, P.R. China

E-mail: wuguozhong@sinap.ac.cn

Key words: carboxymethyl chitosan, PEGylation, folate conjugation, water solubility, folate receptor targeting, targeting drug delivery of solid tumors, including breast cancers and cancers of the digestive organs (2), and has remained the only effective chemotherapy option available for the treatment of colorectal cancer (3). However, in clinical trials of 5-FU, significant adverse effects due to nonspecific activity have been reported (4). Furthermore, as it is degraded in the gastrointestinal tract, 5-FU shows incomplete and unpredictable absorption (4) and a plateau has been reached regarding the drug's efficacy (5). As the number of cancer-related mortalities rises annually, researchers have been working on numerous approaches, including the use of prodrugs $(6,7)$, $\mathrm{pH}$-sensitive polymer coating $(8,9)$ and time-dependent formulations $(10,11)$, in an attempt to identify novel 5-FU carrier systems with more powerful antitumor activity and reduced side effects $(12,13)$. In previous years, 5-FU carrier systems that release 5-FU in situ have attracted the interest of researchers since such systems may circumvent the problem of oral administration of 5-FU in clinical applications $(14,15)$. A number of biodegradable polymers, including azopolymer, pectin and dextrin $(16,17)$, have been explored as potential carriers for 5-FU, and chitosan has emerged as one of the most promising.

Chitosanis composed of randomly distributed $\alpha-(1-4)$-linked D-glucosamine and N-acetyl-D-glucosamine (18). It is generally considered an attractive drug vector due to its biodegradability, biocompatibility, hemostatic, bacteriostatic, fungistatic, anticancer and anticholesteremic properties, as well as its reasonable cost $(19,20)$, minimum immunogenicity and low cytotoxicity (21). Furthermore, chitosan contains functional groups that allow simple coupling of extracellular and intracellular targeting ligands (22). However, its poor solubility limits its use as a drug delivery carrier. Therefore, the development of water-soluble chitosan is a prerequisite to its successful implementation in drug delivery (23). Various approaches, including quaternization of the amino group, $\mathrm{N}$-carboxymethylation and PEGylation $(24,25)$, have been adopted to improve the water solubility of chitosan. The anionic natural polymer derivative carboxymethyl chitosan (CMCS) meets the two main requirements for a drug carrier, biodegradability and low toxicity, and may be a promising potential cancer therapy in the future. However, as CMCS is a negatively charged macromolecule, it has difficulty attaching to the negatively-charged cell membrane for internalization. In vivo studies have shown that a near-neutral polyplex surface 
is important to minimize the occurrence of nonspecific interactions in the blood, and to allow the vector to circulate longer in order to reach its target. Thus, it is necessary to attach hydrophilic agents to the polyplex surface to reduce the surface charge and ensure steric stabilization.

It is well-documented that PEG shielding improves circulation time and reduces toxicity $(26,27)$. Furthermore, it has been reported that polyplex PEG chains are capable of reducing interactions with blood and extracellular components $(28,29)$. However, a number of disadvantages have also been reported, including reduced association with cells, diminished cellular uptake and inefficient cell transfection $(30,31)$. Adding targeting ligands to polyplexes has been proposed as an attractive strategy to improve transfection efficiency $(32,33)$. The major advantage of using chitosan as a drug carrier is that it may be easily conjugated to targeting agents, including proteins, transferrin $(34)$, mannose $(35-37)$, folate $(38,39)$ and galactose (40-43).

A number of characteristics render folate acid (FA) an attractive candidate for targeted molecular treatment of tumors. Folate receptors (FR) exhibit limited expression in healthy cells, but are overexpressed on the surface of human cancer cells $(44,45)$. Furthermore, the high affinity of folate to its receptor (45), and its small size, render it eligible for specific cell targeting. Additionally, the ability of FA to bind to its receptor and induce endocytosis is not altered by covalent bonding of small molecules (46). Studies have been conducted that have utilized FRs on the surface of tumor cells for targeted delivery of anticancer drugs, genes and radiopharmaceuticals via FR-mediated endocytosis $(47,48)$. FA has also been used as a ligand with cationic liposomes (49) and other polymers, including chitosan $(38,50)$, poly (L-lysine) $(51,52)$, and polyethyleneimine (53). One study showed that FA may facilitate nanoparticle endocytosis via the FR, resulting in higher transfection yields (38). In addition, it has also been demonstrated that target-specific gene delivery may be enhanced by folate-PEG modified PEI in vitro and in vivo (54-57) with superior performance compared with PEI $(54,56)$. Previously, Benns et al achieved a notable antitumor effect through intro-tumor administration of therapeutic genes carried by folate-PEG-PEI (55).

In the current study, 5-FU loaded and folate-conjugated CMCS were synthesized and characterized with a PEG spacer (CMCS-5-FU-PEG-FA). 5-FU coupled to CMCS was quantified using fluorine element analysis. The cytotoxicity of CMCS and CMCS-5-FU and the potential of CMCS-PEG-FA for use in targeted delivery of 5-FU in vitro were studied. The results showed that 5-FU and folate were successfully coupled to CMCS and that CMCS-g-PEG-folate is a promising non-viral vector for targeted delivery of chemotherapeutic agents to tumors. Future clinical applications the CMCS-5-FU-PEG-FA system is likely to aid in the goal of releasing $5-\mathrm{FU}$ in situ to treat cancer.

\section{Materials and methods}

Materials. CMCS (Mw, 10,000-30,000 Da) was purchased from Sigma-Aldrich (Shanghai, China). $\mathrm{NH}_{2}$-PEG-FA (Mn, 3,400 Da) was provided by Jiaerke Co (Changzhou, China). Dialysis tubing with a Mw cut-off of 500-1,000 Da was purchased from Spectrum Laboratories (Miami, FL, USA). Cell culture media and supplements, fetal bovine serum (FBS), alamarBlues, FA dihydrate and other general-use chemicals were all purchased from Sigma-Aldrich. Unless stated otherwise, all reagents and solvents were commercially available analytic-grade reagents and were used without further purification.

Synthesis of CMCS-5-FU. Solutions of CMCS in distilled water and 5-FU in anhydrous dimethylsulfoxide (DMSO) were respectively prepared and stirred at $55^{\circ} \mathrm{C}$ until CMCS and 5-FU were dissolved completely. Formaldehyde was then added to the solution of 5-FU in anhydrous DMSO. The mixture was stirred at $55^{\circ} \mathrm{C}$ in the dark for $4 \mathrm{~h}$, then added to the solution of CMCS in distilled water and stirred at room temperature for $24 \mathrm{~h}$. Subsequently, the reaction mixture was dialyzed (cellulose acetate with a molecular weight cut off of 8,000-14,000 Da) against water for two days. The resultant product was collected by lyophilization (Fig. 1).

Synthesis of CMCS-g-PEG-folate (CMCS-PEG-FA). Solutions of $\mathrm{NH}_{2}$-PEG-FA and CMCS in distilled water were respectively prepared and stirred at room temperature until $\mathrm{NH}_{2}$-PEG-FA was dissolved completely. Excessive stoichiometric formaldehyde was added to the solution of $\mathrm{NH}_{2}$-PEG-FA in distilled water. The resulting mixture was stirred at room temperature in the dark for $4 \mathrm{~h}$, and then dialyzed against distilled water for 24 h using dialysis tubing with an Mw cut-off of 500-1,000 Da (Spectrum Laboratories, Rancho Dominguez, CA, USA) to separate free formaldehyde. Finally, the dialyzed solution was added to the solution of CMCS in distilled water and stirred at room temperature for $48 \mathrm{~h}$. The resultant product was isolated using dialysis tubing with an Mw cut-off of 8,000-12,000 Da (Spectrum Laboratories) for $48 \mathrm{~h}$, followed by freeze drying (Fig. 2).

Synthesis of CMCS-5-FU conjugated PEG-FA (CMCS-5-FU-PEG-FA). Solutions of CMCS-PEG-FA in distilled water and 5-FU in anhydrous DMSO were respectively prepared and stirred at $55^{\circ} \mathrm{C}$ until CMCS-PEG-FA and 5-FU were dissolved completely. Chemically quantified formaldehyde was then added to the solution of 5-FU in anhydrous DMSO. The resulting mixture was stirred at $55^{\circ} \mathrm{C}$ in the dark for $4 \mathrm{~h}$, and then added to the solution of CMCS-PEG-FA in distilled water and stirred at room temperature for $24 \mathrm{~h}$. The resultant product was isolated using dialysis tubing with a Mw cut-off of 8,000-12,000 Da (Spectrum Laboratories) for $48 \mathrm{~h}$, followed by freeze drying (Fig. 3).

Infrared (IR) spectroscopy. Fourier transform IR spectra of CMCS-PEG-FA, CMCS and $\mathrm{H}_{2} \mathrm{~N}$-PEG-FA were measured over 4,000-400 $\mathrm{cm}^{-1}$ on a Perkin-Elmer Spectrum 2000 instrument (Perkin Elmer, Boston, MA, USA) with KBr sample pellets.

Determination of 5-FU.The extent of 5-FU on CMCS-PEG-FA was evaluated using fluorine element analysis. Briefly, a $100 \mathrm{mg}$ sample was wrapped in ashless paper and placed in a $500 \mathrm{ml}$ oxygen flask containing $5 \mathrm{ml}$ absorbing liquid for combustion. Fluorides in the resultant absorbing liquid were 
<smiles>Cn1cc(F)c(=O)[nH]c1=O</smiles>

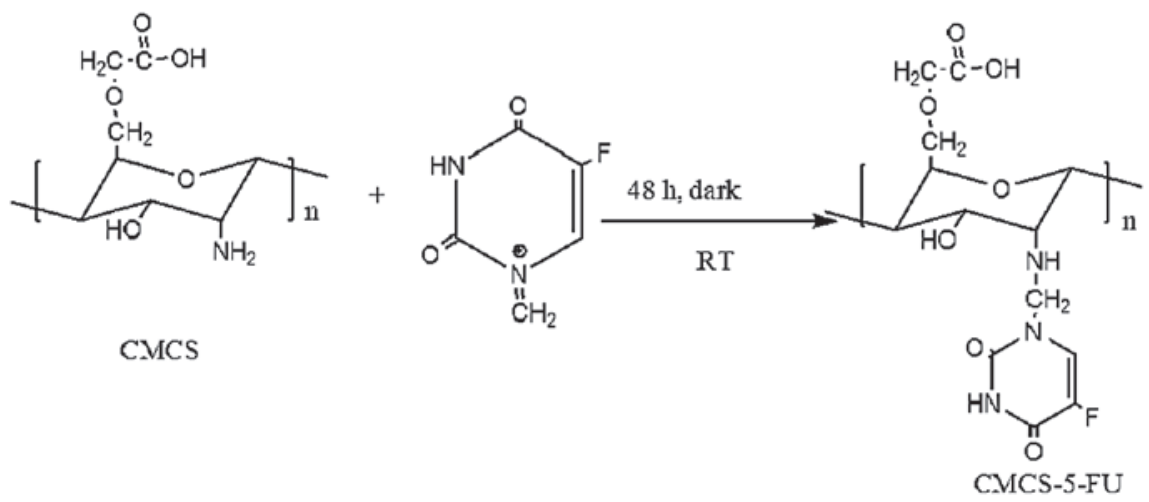

Figure 1. Synthesis of CMCS-5-FU conjugates. CMCS-5-FU, carboxymethil chitosan-5-fluorouracil, DMSO, dimethylsulfoxide; RT, reverse trascription.
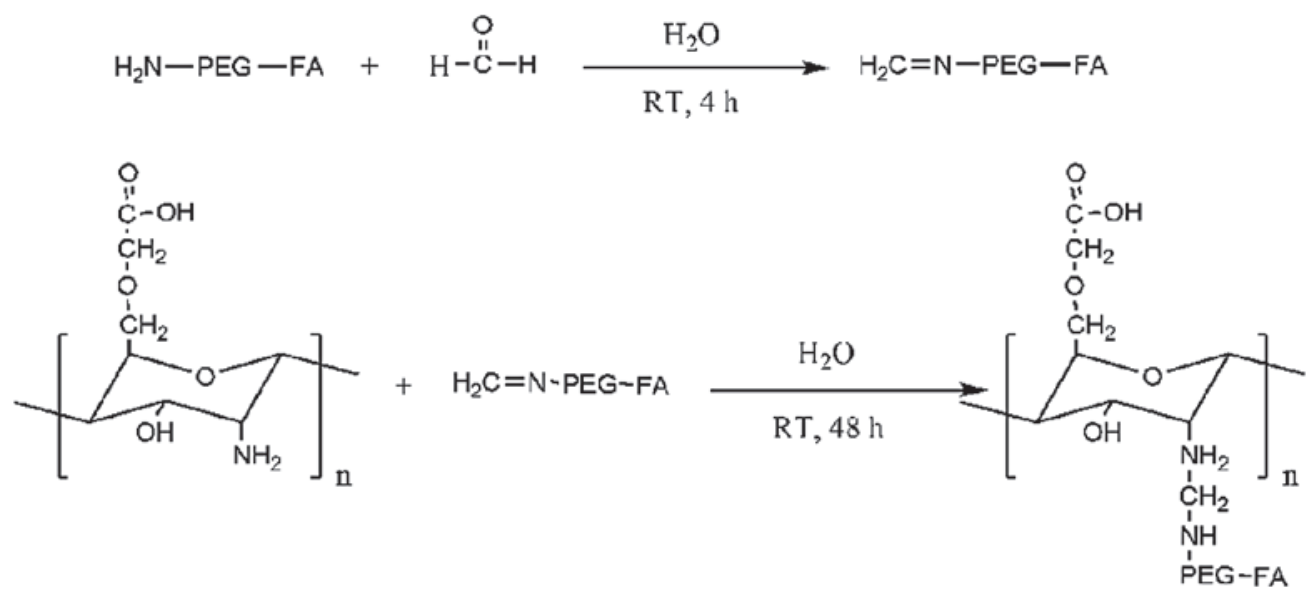

Figure 2. Synthesis of carboxymethyl chitosan-5-fluorouracil conjugated polyethylene glycol-folate acid. RT, reverse transcription.

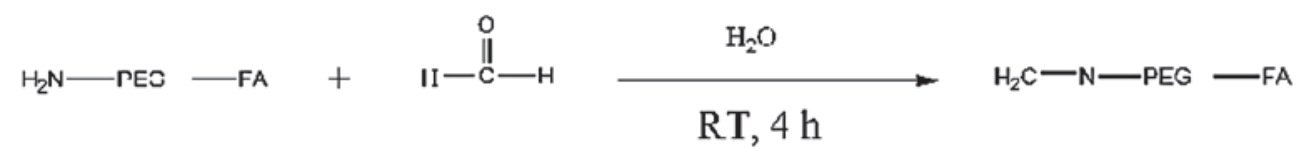

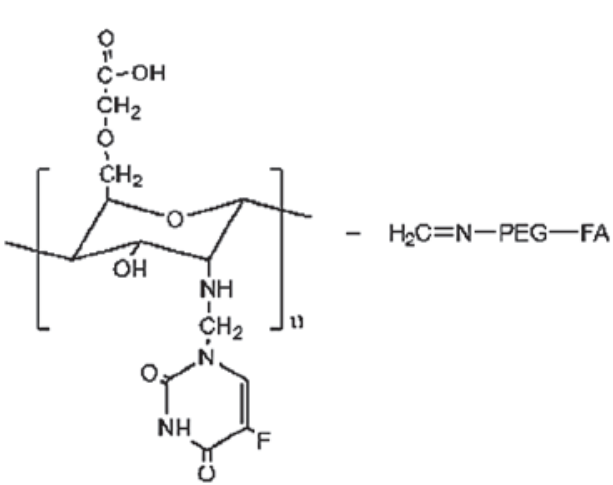

CMCS-5-FU

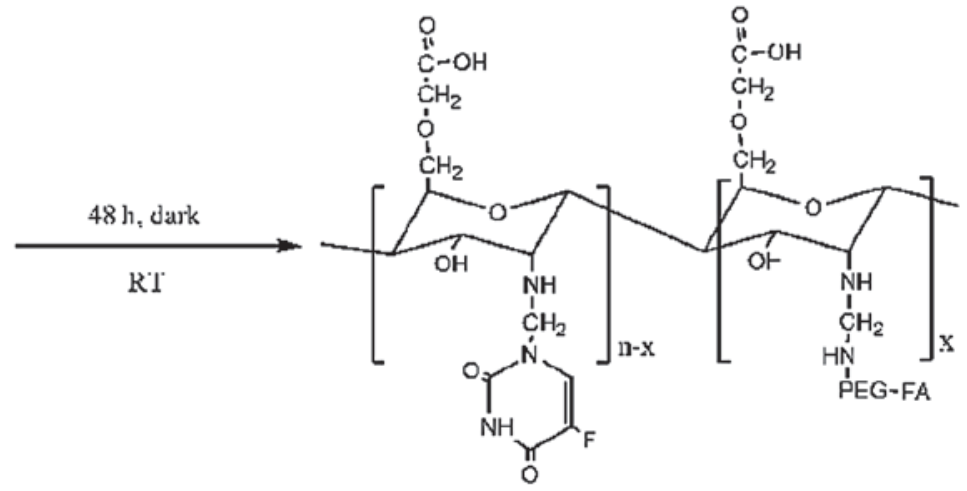

CMCS-5-FU-PEG-FA

Figure 3. Synthesis of carboxymethyl chitosan-5-fluorouracil-polyethylene glycol-folate acid (CMCS-5-FU-PEG-FA). RT, reverse transcription. 




Figure 4. ${ }^{1} \mathrm{H}$ nuclear magnetic resonance spectrum of carboxymethyl chitosan-polyethylene glycol-folate acid dissolved in $\mathrm{D}_{2} \mathrm{O}$.

\section{A}

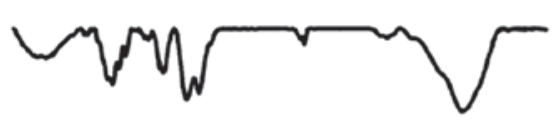

B

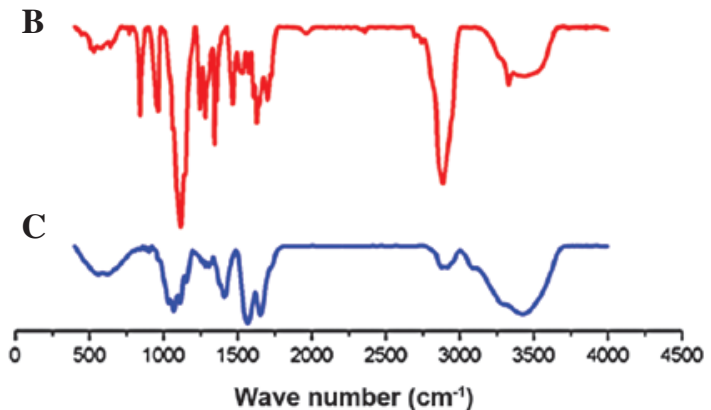

Figure 5. (A) Infrared spectra of $\mathrm{CMCS}$, (B) $\mathrm{NH}_{2}$-PEG-folate and (C) CMCS-PEG-folate. CMCS, carboxymethyl chitosan; PEG, polyethylene glycol.

separated using IonPac AS14-AG14 (Dionex, Sunnyvale, CA, USA) as a separating column and rinsing with solution containing $0.001 \mathrm{M} \mathrm{NaHCO}_{3}+0.0035 \mathrm{M} \mathrm{Na}_{2} \mathrm{CO}_{3}$. The electric conductivity was detected.

${ }^{1} H$ nuclear magnetic resonance (NMR) spectra. The CMCS-PEG-folate structure was confirmed by NMR. The ${ }^{1} \mathrm{H}$ NMR spectra was recorded in $\mathrm{D}_{2} \mathrm{O}$ on a Bruker AC 200P, $200 \mathrm{MHz}$ spectrometer (Bruker Corporation, Rheinstetten, Germany), using tetramethylsilane as the internal standard.

Cell culture. AGS, A549, HepG2 and HeLa cell lines were purchased from the Institute of Biochemistry and Cell Biology, Shanghai Institute for Biological Sciences (Chinese Academy of Sciences, Shanghai, China). AGS cells were cultured in $90 \%$ Ham's F-12K medium supplemented with $10 \%$ heat-inactivated FBS (Gibco-BRL, Gaithersburg, MD, USA), $2 \mathrm{mM}$ L-glutamine and $1.5 \mathrm{~g} / 1 \mathrm{Na}_{2} \mathrm{CO}_{3}$. A549 cells were cultured in medium supplemented with $10 \%$ heat-inactivated FBS, 2 mM L-glutamine and $1.5 \mathrm{~g} / 1 \mathrm{NaHCO}_{3}$. HepG2 were cultured in medium supplemented with $10 \%$ heat-inactivated FBS, $1.0 \mathrm{mM}$ sodium pyruvate, $0.1 \mathrm{mM}$ unessential amino acid and $1.5 \mathrm{~g} / 1 \mathrm{NaHCO}_{3}$. HeLa cells were cultured in Dulbecco's modified Eagle's medium (DMEM) supplemented with $10 \%$ heat-inactivated FBS, $4 \mathrm{mM}$ glutamine, $50 \mathrm{U} / \mathrm{ml}$ penicillin, and $50 \mathrm{mg} / \mathrm{ml}$ streptomycin (cell culture medium). All cells were cultured in a fully humidified atmosphere containing $5 \%$ $\mathrm{CO}_{2}$ at $37^{\circ} \mathrm{C}$.

In vitro cytotoxicity assay. HeLa, A549, HepG2 and AGS cell lines were seeded in a 24-well plate at a density of $\sim 3.0 \times 10^{4}$ cell $/ \mathrm{ml}$ and incubated overnight at $37^{\circ} \mathrm{C}$ and $5 \% \mathrm{CO}_{2}$ to attain subconfluence prior to infection with CMCS or CMCS-5-FU at various concentrations. Three days following infection, cells in each well were exposed to $0.4 \mathrm{ml} 2 \%$ crystal violet in $20 \%$ methanol for $30 \mathrm{~min}$ at room temperature and rinsed with distilled water in preparation for image capturing.

Cellular evaluation of CMCS-PEG-FA targeting ability. The cell-targeting ability of 5-FU-loaded CMCS-PEG-FA was evaluated using HeLa cells, which overexpress the FR, using an 3-(4,5-dimethylthiazol-2-yl)-2,5-diphenyltetrazolium bromide (MTT) assay. HeLa cells were seeded in 96-well plates at a density of $1 \times 10^{4}$ cells/well in $100 \mu$ cell culture medium and incubated overnight to obtain $75-80 \%$ confluency. The culture medium was then replaced with fresh, serum-free medium, and a serial sample of 5-FU-CMCS or 5-FU-CMCS-PEG-FA was added to the cells. Cells were incubated with 5-FU-CMCS or 5-FU-CMCS-PEG-FA at a concentration of $1 \mathrm{mg} / \mathrm{ml}$ with respect to the originally seeded cells at $37^{\circ} \mathrm{C}$. Cells were incubated for a further $72 \mathrm{~h}$. A total of $10 \mu \mathrm{l}$ MTT solution $(5 \mathrm{mg} / \mathrm{ml})$ was added to the $100 \mu \mathrm{l}$ of culture medium in each well prior to incubation at $37^{\circ} \mathrm{C}$ for $4 \mathrm{~h}$. The MTT-containing medium was replaced with $100 \mu \mathrm{l}$ solubilization solution DMSO. Finally, the absorbance was measured at $595 \mathrm{~nm}$ using an ELISA plate reader (Thermo Fisher, Waltham, MA, USA) with a reference filter of $650 \mathrm{~nm}$. Viability of non-treated control cells was arbitrarily defined as $100 \%$. The experiment was repeated three times for each sample treatment. Cell viability $(\%)$ was calculated from the following equation (i): $\left[\mathrm{OD}_{595 \text { (sample) }}-\mathrm{OD}_{595 \text { (sample) }}\right] /\left[\mathrm{OD}_{595 \text { (control) }}-\mathrm{OD}_{650 \text { (control) }}\right]$ 

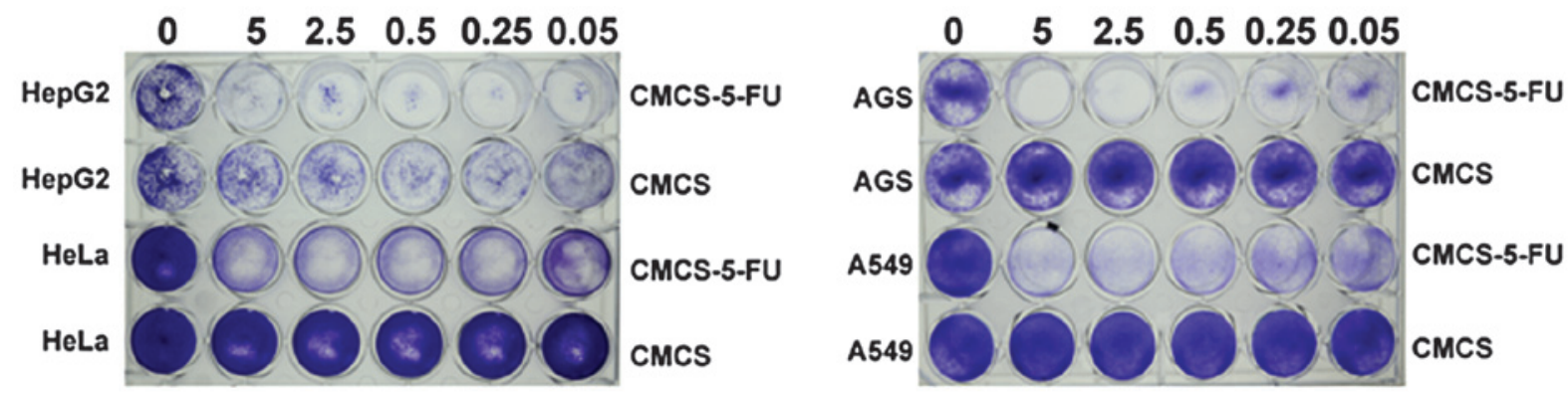

Figure 6. Cytopathic effect of CMCS or CMCS-5-FU on tumor cell. AGS, A549, HeLa and HepG2 tumor cell lines were seeded in 24-well plates at a density of $5 \times 10^{4}$ cells for each well and incubated with CMCS or CMCS-5-FU at the indicated concentration $(\mathrm{mg} / \mathrm{ml})$. Following $72 \mathrm{~h}$, cells were stained with crystal violet. CMCS, carboxymethyl chitosan; 5-FU, 5-fluorouracil.

x100, (i) where $\mathrm{OD}_{595 \text { (sample) }}$ and $\mathrm{OD}_{650 \text { (sample) }}$ represent measurements from the wells treated with CMCS-5-FU or (CMCS-5-FU)-PEG-FA complex and $\mathrm{OD}_{595(\mathrm{control})}$ and $\mathrm{OD}_{650 \text { (control) }}$ represent measurements from the wells treated with only DMEM containing $10 \%$ fetal calf serum.

Statistical analysis. All experiments were repeated four times and measurements were collected in quadruplicate. Data are expressed as the mean \pm standard deviation based on four measurements. Statistical analysis was performed using Student's t-test. $\mathrm{P}<0.005$ was considered to indicate a statistically significant difference.

\section{Results and discussion}

Synthesis and characterization of CMCS-5-FU, $C M C S-P E G-F A$ and CMCS-5-FU-PEG-FA. The analysis by ${ }^{1} \mathrm{H}$ NMR (Fig. 4) confirmed the structure of the expected poly-CMCS-PEG-folate copolymer. Fig. 1 shows the ${ }^{1} \mathrm{H}$ NMR spectrum of the poly-CMCS-PEG-folate copolymer. From the result of ${ }^{1} \mathrm{H}$ NMR spectrum, it was observed that the peak at $3.54 \mathrm{ppm}$ was assigned to the protons in the ethylene groups -O- $\mathrm{CH}_{2}-\mathrm{CH}_{2}-\mathrm{O}$ - of the PEG units. The signal appeared at 2.95-3.10 was corresponding to the monosaccharide residue (-CH-NH-). The signal at 2.45-2.60 ppm was attributed to the signal of $-\mathrm{NH}-\mathrm{CH}_{2}-\mathrm{CH}_{2} \mathrm{O}-$. It is evident that the proton peaks of 6.7-8.8 ppm were observed in the ${ }^{1} \mathrm{HNMR}$ spectrum of CMCS-PEG-FA, confirming the successful conjugation of $\mathrm{H}_{2} \mathrm{~N}-\mathrm{PEG}-\mathrm{FA}$ with CMCS. These results obtained are consistent with the expected chemical structure of the copolymers. The relevant signals of folate were weaker than the broad and marked proton signals of PEG and CMCS residues, producing more accurate evaluations. IR spectroscopy was performed to further confirm the successful coupling of $\mathrm{NH}_{2}$-PEG-folate to CMCS. The content of coupled 5-FU was determined by fluorine element analysis.

IR spectroscopy. The formation of CMCS-PEG-folate was confirmed using Fourier transform infrared spectroscopy. IR spectra in the amino group and hydroxyl group stretching region of $\mathrm{CMCS}, \mathrm{NH}_{2}-\mathrm{PEG}$-folate and CMCS-PEG-FA systems, with or without reaction, are presented in Fig. 2. Characteristics of IR bands of $\mathrm{H}$-form CMCS is shown in Fig. 5A. The peaks at $1,652.62 \mathrm{~cm}^{-1}(-\mathrm{COOH})$, $1,031.08-1,153.05 \mathrm{~cm}^{-1}(\mathrm{C}-\mathrm{O})$ indicated the characteristics

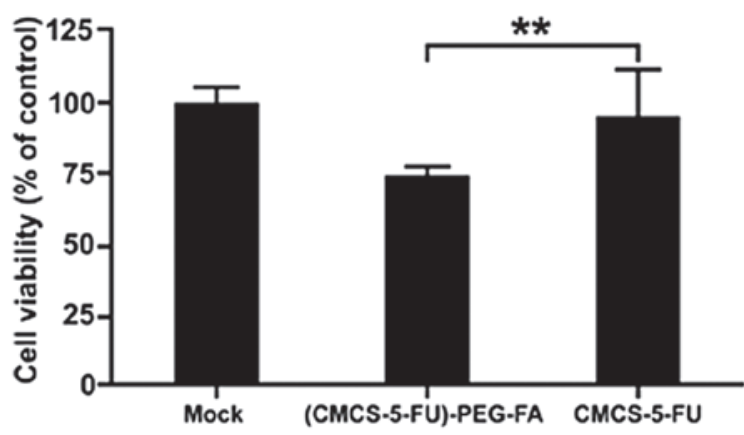

Figure 7. Cytotoxicity of CMCS-5-FU-PEG-folate and CMCS-5-FU. HeLa cells were infected with CMCS-5-FU-PEG-folate or CMCS-5-FU at a concentration of $10 \mathrm{mg} / \mathrm{ml}$. After $72 \mathrm{~h}$, the HeLa cell survival ratios were determinate by MTT assay. Results were expressed as a relative percentage to untreated control HeLa cells and represent the mean of four repetitive experiments. Errors bar, standard deviation. ${ }^{* *} \mathrm{P}<0.005$, vs. CMCS-5-FU-PEG-FA. CMCS, carboxymethyl chitosan; 5-FU, 5-fluorouracil; PEG, polyethylene glycol; FA, folate acid.

of O-CMCS. The IR spectrum of $\mathrm{NH}_{2}$-PEG-FA (Fig. 5B) revealed peaks at $3328.39 \mathrm{~cm}^{-1}\left(\mathrm{~N}-\mathrm{H}\right.$ stretch), $1280.71 \mathrm{~cm}^{-1}$ (O-H deflection), $2885.46 \mathrm{~cm}^{-1}$ (C-H stretch), $1243.40 \mathrm{~cm}^{-1}$ (C-O deflection) and $1114.18 \mathrm{~cm}^{-1}$ (marked peak of $\mathrm{C}-\mathrm{O}$ stretch of ether). Following the conjugation of FA-PEG-NH $\mathrm{N}_{2}$ with CMCS, the spectrum of the resultant molecules (Fig. 5C) shows the characteristic bands of the original CMCS and also the characteristic peaks of the FA at $1,652.62 \mathrm{~cm}^{-1}\left(-\mathrm{CONH}\right.$ amide band II) and $1,568.08 \mathrm{~cm}^{-1}$ (-NH amide band II) (Fig. 5C). Furthermore, the absorption of amide band II at $1,652.62 \mathrm{~cm}^{-1}$ increased. Bands at $1698.70 \mathrm{~cm}^{-1}$ were due to the $\mathrm{C}=\mathrm{O}$ stretching vibration of carboxylic acid in FA and bands between 1155.26 and $1068.12 \mathrm{~cm}^{-1}$ were attributed to the $\mathrm{C}-\mathrm{O}-\mathrm{C}$ stretching vibration of ether in $\mathrm{CMCS}$, demonstrating that $\mathrm{CH}_{2}=\mathrm{N}-\mathrm{PEG}-\mathrm{FA}$ binds chemically to CMCS. A marked modification of the absorption pattern was observed, where the typical hydroxyl group and amino group stretching band at $3423.73 \mathrm{~cm}^{-1}$ appeared markedly reduced, demonstrating the substitution of $\mathrm{H}$ in the hydroxyl or amino group on the CMCS by $\mathrm{N}$ of the $\mathrm{NH}_{2}$-PEG-FA or 5-FU.

Determination of 5-fluorouracil content. To determinate the percentage of 5-FU grafted to (CMCS-5-FU)-PEG-FA, the fluorine element analysis was conducted following freeze 
drying of the conjugate. The result obtained indicated that there was $0.332 \mathrm{mg}$ 5-FU in $1 \mathrm{~g}$ (CMCS-5-FU)-PEG-FA.

In vitro cytotoxicity of CMCS-5-FU and CMCS. For the concerns of efficient drug delivery, biocompatibility and cytotoxicity of the CMCS or 5-FU loaded CMCS, four cell lines (AGS, SW480, HeLa and A549) were selected for the in vitro cytotoxicity investigation using the crystal violet assay. The cells were incubated with CMCS or 5-FU loaded CMCS in the medium for $72 \mathrm{~h}$. Crystal violet stain was used to assay cell viabilities in the presence of CMCS or 5-FU loaded CMCS, using cells untreated with CMCS or 5-FU loaded CMCS as the control.

As illustrated in Fig. 6, for CMCS, cell viabilities are $100 \%$, which indicates that there is no cytotoxicity of CMCS against the four selected cell lines AGS, A549, HeLa and HepG2, and the results obtained were consistent with the reported results in the literature that demonstrated that chitosan exhibits no toxicity in in vitro (58) and in vivo (22) experiments. However, 5-FU loaded CMCS Exhibited a marked inhibitive effect on AGS, A549, HeLa and HepG2 cell lines, suggesting that the powerful antitumor potential is retained when 5-FU is covalently linked to CMCS and maintains the antitumor ability. Furthermore, at the same concentration, there was an extent of difference in the cytotoxicity of 5-FU loaded CMCS to the four cancer cell lines selected, indicating that the antitumor ability of 5-FU loaded CMCS has an association with cancer cell types. In conclusion, 5-FU was successfully linked to CMCS and 5-FU covalent linkage with CMCS did not affect its antitumor potential.

Cellular evaluation of CMCS-PEG-FA targeting ability. To determine whether folate acid conjugated with CMCS may effectively target and improve of the rate of drug uptake by cancer cells, in vitro targeted delivery of 5-FU was investigated by MTT assay in $\mathrm{FR}^{+}$HeLa cells with phosphate-buffered saline as the control.

The results of the MTT assay revealed that differences in cytotoxicity between CMCS-5-FU and CMCS-5-FU-PEG-FA were significantly larger for $\mathrm{FR}^{+} \mathrm{HeLa}$ cell lines (Fig. 7). These results may be attributed to the involvement of the FR in cellular association and endocytosis of CMCS-5-FU-PEG-FA in $\mathrm{FR}^{+}$cells.

In conclusion, in the current study, 5-FU and FA-PEG-NH were successfully grafted onto CMCS. CMCS showed no toxicity against HeLa, AGS, A549 or HepG2 cells. The feasibility of using CMCS-PEG-folate to deliver 5-FU in a targeted manner to FR-bearing HeLa cancer cells was confirmed. FA-PEG-CMCS may be a promising carrier for the targeted delivery of chemotherapeutic agents to FR-bearing tumor cells. Further studies are in progress in our laboratory to test this novel targeted drug delivery system in vivo.

\section{Acknowledgements}

The authors would like to thank Professor Lanyin Sun for her technical assistance, Mr. Zewen Ye for ${ }^{1} \mathrm{H}$ NMR spectrum and IR spectroscopy analyses, Mr. Xing Ze for illustration, and Dr Guoxin Zhang, Dr Mouhua Wang and Dr Weihua Liu for discussions. Professional English proof reading by Mrs. Sarash is also acknowledged.

\section{References}

1. Heidelberger C, Chaudhuri NK, Danneburg P, et al: Fluorinated pyrimidines, a new class of tumour-inhibitory compounds. Nature 179: 663-666, 1957.

2. Cai TB, Tang X, Nagorski J, Brauschweiger PG and Wang PG: Synthesis and cytotoxicity of 5-fluorouracil/diazeniumdiolate conjugates. Bioorg Med Chem 11: 4971-4975, 2003.

3. No authors listed: Efficacy of adjuvant fluorouracil and folinic acid in colon cancer. International Multicentre Pooled Analysis of Colon Cancer Trials (IMPACT) investigators. Lancet 345: 939-944, 1995.

4. Lin FH, Lee YH, Jian CH, Wong JM, Shieh MJ and Wang CY: A study of purified montmorillonite intercalated with 5-fluorouracil as drug carrier. Biomaterials 23: 1981-1987, 2002.

5. Bleiberg H: Colorectal cancer - is there an alternative to 5-FU? Eur J Cancer 33: 536-541, 1997.

6. Riley SA and Turnberg LA: Sulphasalazine and the aminosalicylates in the treatment of inflammatory bowel disease. Q J Med 75: 551-562, 1990.

7. Bartalsky A: Salicylazobenzoic acid in ulcerative colitis. Lancet 319: 960, 1982.

8. Ashford M, Fell J, Attwood D, Sharma H and Woodhead P: In vitro investigation into the suitability of $\mathrm{pH}$ dependent polymer for colonic targeting. Int J Pharm 95: 193-199, 1993.

9. Marvola M, Nykänen P, Rautio S, Isonen N and Autere AM: Enteric polymers as binders and coating materials in multiple-unit site-specific drug delivery systems. Eur J Pharm Sci 7: 259-267, 1999.

10. Gazzaniga A, Busetti C, Sangali ME and Giordana ME: Time-dependent oral delivery system for colonic targeting system for the colon targeting. STP Pharma Sci 5: 83-88, 1995.

11. Gazzaniga A, Iamartino P, Maffione G and Sangal ME: Oral delayed release system system for colonic specific delivery. Int J Pharm 108: 77-83, 1994.

12. Malet-Martino M and Martino R: Clinical studies of three oral prodrugs of 5-fluorouracil (capecitabine, UFT, S-1): a review. Oncologist 7: 288-323, 2002.

13. Malet-Martino M, Jolimaitre P and Martino R: The prodrugs of 5-fluorouracil. Curr Med Chem Anticancer Agents 2: 267-310, 2002.

14. Haller DG: An overview of adjuvant therapy for colorectal. Eur J Cancer 31A: 1255-1263, 1995.

15. Bajetta E, Di Bartolomeo M, Somma L, Del Vecchio M, Artale S, Zunino F, Bignami P, Magnani E and Buzzoni R: Doxifluridine in colorectal cancer patients resistant to 5-fluorouracil (5-FU) containing regimens. Eur J Cancer 33: 687-690, 1997.

16. Hovgaard L and Brondsted H: Dextran hydrogels for colon-specific drug delivery. J Control Release 36: 159-166, 1995.

17. Watts PJ and Lllum L: Colonic drug delivery. Drug Dev Ind Pharm 23: 893-913, 1997.

18. Saranya N, Moorthi A, Saravanan S, Devi MP and Selvamurugan N: Chitosan and its derivatives for gene delivery. Int J Biol Macromol 48: 234-238, 2011.

19. Lee KY, Kwon IC, Kim YH, Jo WH and Jeong SY: Preparation of chitosan self-aggregates as a gene delivery system. J Control Release 51: 213-220, 1998.

20. Hejazi R and Amiji M: Chitosan-based gastrointestinal delivery system. J Control Release 89: 151-165, 2003.

21. Mansouri S, Lavigne P, Corsi K, Benderdour M, Beaumont E and Fernandes JC: Chitosan-DNA nanoparticles as non-viral vectors in gene therapy: strategies to improve transfection efficacy. Eur J Pharm Biopharm 57: 1-8, 2004.

22. Dang JM and Leong KW: Natural polymers for gene delivery and tissue engineering. Adv Drug Deliv Rev 58: 487-499, 2006.

23. Chung YC, Kuo CL and Chen CC: Preparation and important functional properties of water-soluble chitosan produced through Maillard reaction. Bioresour Technol 96: 1473-1482, 2005.

24. Liu WG, Zhang X, Sun SJ, Sun GJ, Yao KD, Liang DC, Guo G and Zhang JY: N-alkylated chitosan as a potential nonviral vector for gene transfection. Bioconjug Chem 14: 782-789, 2003.

25. Mao S, Shuai X, Unger F, Wittmar M, Xie X and Kissel T: Synthesis, characterization and cytotoxicity of poly(ethylene glycol)-graft-trimethyl chitosan block copolymers. Biomaterials 26: 6343-6356, 2005.

26. Gref R, Lück M, Quellec P, Marchand M, Dellacherie E, Harnisch S, et al: 'Stealth' corona-core nanoparticles surface modified by polyethylene glycol (PEG): influences of the corona (PEG chain length and surface density) and of the core composition on phagocytic uptake and plasma protein adsorption. Colloids Surf B Biointerfaces 18: 301-313, 2000. 
27. Kircheis R, Schüller S, Brunner S, Ogris M, Heider KH, Zauner W, et al: Polycation-based DNA complexes for tumor-targeted gene delivery in vivo. J Gene Med 1: 111-120, 1999.

28. Ogris M, Brunner S, Schuller S, Kircheis R and Wagner E: PEGylated DNA/transferrin-PEI complexes: reduced interaction with blood components, extended circulation in blood and potential for systemic gene delivery. Gene Ther 6: 595-605, 1999.

29. Oupický D, Ogris M and Seymour LW: Development of long-circulating polyelectrolyte complexes for systemic delivery of genes. J Drug Target 10: 93-98, 2002.

30. Nguyen HK, Lemieux P, Vinogradov SV, Gebhart CL, Guérin N, Paradis G, et al: Evaluation of polyether-polyethyleneimine graft copolymers as gene transfer agents. Gene Ther 7: 126-138, 2000 .

31. Choi YH, Liu F, Kim JS, Choi YK, Park JS and Kim SW: Polyethylene glycol-grafted poly-L-lysine as polymeric gene carrier. J Control Release 54: 39-48, 1998.

32. Fernandez-Megia E, Novoa-Carballal R, QuiñoáE and Riguera R Conjugation of bioactive ligands to PEG-grafted chitosan at the distal end of PEG. Biomacromolecules 8: 833-842, 2007.

33. Ogris M, Walker G, Blessing T, Kircheis R, Wolschek M and Wagner E: Tumor-targeted gene therapy: strategies for the preparation of ligand-polyethylene glycol-polyethylenimine/DNA complexes. J Control Release 91: 173-181, 2003.

34. Mao HQ, Roy K, Troung-Le VL, Janes KA, Lin KY, Wang Y, et al: Chitosan-DNA nanoparticles as gene carriers: synthesis, characterization and transfection efficiency. J Control Release 70: 399-421, 2001

35. Kim TH, Nah JW, Cho MH, Park TG and Cho CS: Receptor-mediated gene delivery into antigen presenting cells using mannosylated chitosan/DNA nanoparticles. J Nanosci Nanotechnol 6: 2796-2803, 2006.

36. Hashimoto M, Morimoto M, Saimoto H, Shigemasa Y, Yanagie H, Eriguchi $\mathrm{M}$ and Sato T: Gene transfer by DNA/mannosylated chitosan complexes into mouse peritoneal macrophages. Biotechnol Lett 28: 815-821, 2006.

37. Wada K, Arima H, Tsutsumi T, Chihara Y, Hattori K, Hirayama F and Uekama K: Improvement of gene delivery mediated by mannosylated dendrimer/alpha-cyclodextrin conjugates J Control Release 104: 397-413, 2005.

38. Mansouri S, Cuie Y, Winnik F, Shi Q, Lavigne P, Benderdour M, et al: Characterization of folate-chitosan-DNA nanoparticles for gene therapy. Biomaterials 27: 2060-2065, 2006.

39. Lee D, Lockey R and Mohapatra S: Folate receptor-mediated cancer cell specific gene delivery using folic acid-conjugated oligochitosans. J Nanosci Nanotechnol 6: 2860-2866, 2006.

40. Murata J, Ohya Y and Ouchi T: Design of quaternary chitosan conjugate having antennary galactose residues as a gene delivery tool. Carbohydr Polym 32: 105-119, 1997.

41. Gao S, Chen J, Xu X, Ding Z, Yang YH, Hua Z and Zhang J: Galactosylated low molecular weight chitosan as DNA carrier for hepatocyte-targeting. Int J Pharm 255: 57-68, 2003.

42. Kim TH, Park IK, Nah JW, Choi YJ and Cho CS: Galactosylated chitosan/DNA nanoparticles prepared using water-soluble chitosan as a gene carrier. Biomaterials 25: 3783-3792, 2004.
43. Hashimoto M, Morimoto M, Saimoto H, Shigemasa $Y$ and Sato T: Lactosylated chitosan for DNA delivery into hepatocytes: the effect of lactosylation on the physicochemical properties and intracellular trafficking of pDNA/chitosan complexes. Bioconjug Chem 17: 309-316, 2006.

44. Weitman SD, Lark RH, Coney LR, Fort DW, Frasca V, Zurawski VR Jr and Kamen BA: Distribution of the folate receptor GP38 in normal and malignant cell lines and tissues. Cancer Res 52: 3396-3401, 1992.

45. Antony AC: Folate receptors. Annu Rev Nutr 16: 501-521, 1996.

46. Lee RJ and Low PS: Delivery of liposomes into cultured KB cells via folate receptor-mediated endocytosis. J Biol Chem 269: 3198-3204, 1994.

47. Lee RJ and Low PS: Folate-mediated tumor cell targeting of liposome-entrapped doxorubicin in vitro. Biochem Biophys Acta 1233: 134-144, 1995.

48. Ross JF, Chaudhuri PK and Ratnam M: Differential regulation of folate receptor isoforms in normal and malignant tissues in vivo and in established cell lines. Physiologic and clinical implications. Cancer 73: 2432-2443, 1994.

49. Kamaly N, Kalber T, Thanou M, Bell JD and Miller AD: Folate receptor targeted bimodal liposomes for tumor magnetic resonance imaging. Bioconjug Chem 20: 648-655, 2009.

50. Zheng Y,CaiZ, Song X, Chen Q, Bi Y,Li Y and Hou S: Preparation and characterization of folate conjugated $\mathrm{N}$-trimethyl chitosan nanoparticles as protein carrier targeting folate receptor: in vitro studies. J Drug Target 17: 294-303, 2009.

51. Hwa Kim S, Hoon Jeong J, Chul Cho K, Wan Kim S and Gwan Park T: Target-specific gene silencing by siRNA plasmid DNA complexed with folate-modified poly(ethylenimine). J Control Release 104: 223-232, 2005.

52. Hwa Kim S, Hoon Jeong J, Joe Co and Gwan Park T: Folate receptor mediated intracellular protein delivery using PLL-PEG-FOL conjugate. J Control Release 103: 625-634, 2005.

53. Liang B, He ML, Xiao ZP, et al: Synthesis and characterization of folate-PEG-grafted-hyperbranched-PEI for tumor-targeted gene delivery. Biochem Biophys Res Commun 367: 874-880, 2008

54. Benns JM, Mahato RI and Kim SW: Optimization of factors influencing the transfection efficiency of folate-PEG-folate-graft-polyethylenimine. J Control Release 79: 255-269, 2002.

55. Benns JM, Maheshwari A, Furgeson DY, Mahato RI and Kim SW: Folate-PEG-folate-graft-polyethylenimine-based gene delivery. J Drug Target 9: 123-139, 2001

56. Cheng $\mathrm{H}$, Zhu JL, Zeng X, Jing Y, Zhang XZ and Zhuo RX: Targeted gene delivery mediated by folate-polyethylenimine-block-poly(ethylene glycol) with receptor selectivity. Bioconjug Chem 20: 481-487, 2009.

57. Kim SH, Mok H, Jeong JH, Kim SW and Park TG: Comparative evaluation of target-specific GFP gene silencing efficiencies for antisense ODN, synthetic siRNA, and siRNA plasmid complexed with PEI-PEG-FOL conjugate. Bioconjug Chem 17: 241-244, 2006.

58. Corsi K, Chellat F, Yahia L and Fernandes JC: Mesenchymal stem cells, MG63 and HEK293 transfection using chitosan-DNA nanoparticles. Biomaterials 24: 1255-1264, 2003. 